\title{
What We have Learned from Fetal Neurophysiology?
}

\author{
Aida Salihagić-Kadić, Maja Predojevic
}

\begin{abstract}
The nervous system is one of the earliest emerging systems in fetal development. Due to progress of modern imaging technologies, such as ultrasound, a growing pool of information on the development of the central nervous system (CNS) and fetal behavioral patterns has been made available. The major events in the development of the CNS, fetal motor and sensory development as well as fetal response to stress are discussed in this review. The fetus is not entirely protected from harmful influence of the external factors. Postnatal follow-up studies have showed that many environmental influences causing the fetal stress can interfere with the fetal neurodevelopment and leave long-term and profound consequences on brain structure and function.
\end{abstract}

Keywords: Fetal brain, Fetal behavior, Neuromotor development, Neurosensory development.

How to cite this article: Salihagić-Kadić A, Predojevic M. What We have Learned from Fetal Neurophysiology? Donald School J Ultrasound Obstet Gynecol 2012;6(2):179-188.

Source of support: This work was supported by a grant from the Ministry of Science, Education and Sport of the Republic of Croatia.

Conflict of interest: None declared

\section{INTRODUCTION}

Ultrasonic studies have discovered the fascinating diversity of fetal intrauterine activities. In addition fetal activities observed or recorded with ultrasonic equipment can be defined as fetal behavior. It has been shown that fetal activity occurs far earlier than the mother can feel it, in fact as early as the late embryonic period. During intrauterine period, the fetus gradually begins to perform many vital physiologic functions. Repertoire of fetal functions and activities constantly expands, reflecting the maturation of the fetal central nervous system (CNS). Furthermore, basic and clinical research into fetal neurophysiology revealed that the fetus reacts to painful stimuli and the mother's emotions; it has a developed sense of taste as well as that of smell. The fetus responds to sounds, recognizes the mother's voice, reacts to light and touch with weaker or stronger movements, and with changes in the heart rate. The stimulating intrauterine environment has a profound effect on fetal brain development. If not optimal, due to vulnerability of the developing neuronal system, disruptions in the brain development can occur, which can cause immediate damage or leave, at the moment invisible, but long-term consequences on mental health.

\section{FETAL MOTOR DEVELOPMENT}

Analysis of the fetal motoric patterns in comparison with morphological studies led to the conclusion that fetal motility directly reflects developmental and maturational processes of the CNS. ${ }^{1}$ Furthermore, recent studies revealed that fetal motility plays an important role in the development of organs and organ systems, such as the CNS, muscles, lungs, retina and gastrointestinal tract. ${ }^{2}$

\section{Development in the First Trimester}

Early embryonic development is characterized by the immobility of an embryo. However, between 7 and 15 weeks of gestation, most types of movement pattern will emerge. ${ }^{3}$

A prerequisite for the establishment of embryonic motility is the development of interneuronal connections. The first synapses can be detected in the spinal cord at 6 to 7 weeks of gestation and the first spontaneous movements can be observed shortly after. ${ }^{4}$ At the same time, with the inception of spontaneous vermicular movements, at the 7.5th week of gestation, the earliest motor reflex activity can be detected, representing the existence of the first afferent-efferent circuits in the spinal cord. ${ }^{5}$ Further, general movements, which are the first complex, wellorganized movement pattern, and involve head, trunk and limb movements, can be seen from 8 to 9 weeks of gestation onward. ${ }^{2,6}$

It is very important to note that even at this early stage of development, embryonic and fetal movements appear in recognizable temporal sequences without any amorphous or random movement. The explanation for this fascinating phenomenon lies in the intrinsic properties of neurons. That means that neural cells begin to generate and propagate action potentials as soon as they interconnect. ${ }^{7}$ The interconnected neurons generate patterned activity because of endogenous properties of the neurons. ${ }^{8}$ Investigations have shown that neurons are able to communicate through nonsynaptic mechanisms even before the onset of synapsogenesis. $^{9-11}$

The brain stem, which consists of the medulla oblongata, pons and midbrain, is fashioned around the 7th week of gestation and main parts of the diencephalon and cerebral hemispheres are formed by the end of the 8th gestational week. $^{12,13}$ As the medulla matures ahead of more rostral structures of the brain stem, reflexive movements of the head, body, extremities as well as breathing-like movements and alterations in heart rate, come into view prior to other functions. Facial movements, which are also controlled by cranial nerves $\mathrm{V}$ and VII, emerge around 10 to 11 weeks $^{12}$ (Table 1). From 10 weeks onward, the number and frequency 
of fetal movements increase and the repertoire of movements begins to expand. ${ }^{2}$

At 10 weeks of gestation lateralized behavior may be observed, and the fetus begins to demonstrate the earliest signs of right- or left-handedness. Stimulation of the brain is known to influence brain organization and it is considered that fetal motor activity may eventually stimulate the brain to develop 'handedness' and subsequent lateralization of the function. ${ }^{14,15}$ From 13 gestational weeks onward, a 'goal orientation' of hand movements appears and a target point can be recognized for each hand movement. ${ }^{16}$ Finally, at 13 to 14 weeks, isolated finger movements can be observed. $^{17}$

Our longitudinal study, performed by 4D ultrasound in 100 fetuses from all trimesters of normal pregnancies, has shown increasing frequency of general movements, isolated arm and leg movements, stretching as well as head movements during the first trimester. Only the startle movement pattern seemed to occur stagnantly in this period of gestation. ${ }^{18}$ General movements were found to be the most frequent movement pattern in the first trimester of normal pregnancies. ${ }^{19}$

\section{Development in the Second Trimester}

In the second trimester the brain stem continues to mature, resulting in expansion and complexity of the behavioral patterns. Early in the second trimester, at the 15th week, 16 different types of movement can be observed. The first eye movements appear as sporadic movements with a limited frequency, at 16 to 18 weeks of gestation. The delayed onset of eye movements can be explained with later onset of midbrain maturation. Its maturation begins in the second trimester. ${ }^{2}$

One of the important regions in the developing cortex is the subplate zone, that is a site for transient synapses and neuronal interactions. The development of subplate zone, between the 15th and 17th week of gestation, is accompanied with an increase in the number of cortical synapses, which probably form the substrate for the earliest electrocortical activity at 19 weeks of gestation. ${ }^{20,21}$

From 20 to 22 weeks of gestation fetal movements, breathing activity, and heat rate begin to follow daily cycles called circadian rhythms. ${ }^{22}$ Main control center of the circadian rhythms, the suprachiasmatic nucleus located in the hypothalamus, is developed by midgestation. ${ }^{23}$

The active and diverse fetal motor behavior in the firsthalf of pregnancy is related to the development of neuronal connections, through axonal in-growth, synaptogenesis and dendrite proliferation. However, we have to emphasize that despite the great diversity of fetal motor patterns in this period of pregnancy, and a dynamic pattern of neuronal production and migration, the cerebral circuits are too immature for cerebral involvement in motor behavior. ${ }^{21}$ Nevertheless, the studies of anencephalic fetuses have provided apparent evidence for the influence of supraspinal structures on motor behavior at around the 20th gestational week. In these fetuses the incidence of movements was normal or even increased, but the complexity of movement patterns changed dramatically and movements were stereotyped and simplified. ${ }^{24}$ Similar qualitative changes were described at the 17th gestational week in fetuses with cerebral aplasia, and at 18 weeks in fetuses with hydrocephalus. ${ }^{25}$

At the 20th week, the spinothalamic tract is established and myelinized by 29 weeks of gestation, and thalamocortical connections penetrate the cortical plate at 24 to 26 weeks. ${ }^{26,27}$ The lower motor control system, consisting of the brainstem and cerebellum, begins maturation at the 24th gestational week and becomes accessible to clinical estimation at about 28 weeks. ${ }^{28}$

The second-half of pregnancy is characterized by gradual organization of fetal movement patterns (Table 1). The periods of fetal quiescence begin to increase, and the restactivity cycles become recognizable. ${ }^{2}$

\section{Development in the Third Trimester}

According to our results, the most frequent facial movement patterns in the second trimester were isolated eye blinking pattern (with a peak frequency at 28 weeks of gestation), grimacing, sucking and swallowing ${ }^{18}$ (Table 1 ).

Between 26 and 28 weeks, evoked potentials can be registered from the cortex, indicating that the functional connection between periphery and cortex operates from that time onward. ${ }^{29}$ The upper motor control system, consisting of the cerebral hemispheres and basal ganglia, matures later than the lower system, and clinically emerges at 34 weeks of gestation. ${ }^{28}$ Approximately between 24 and 34 weeks, cortical areal differentiation begins and continues until the end of gestation. ${ }^{21}$ Neuronal differentiation and the laminar distribution of the thalamocortical axons lead to the appearance of six-layered lamination throughout the neocortex after 32 weeks of gestation. ${ }^{30}$ However, it is important to point out that the cerebral cortex is still very immature and until delivery, subunits of the brainstem remain the main regulators of all fetal behavioral patterns. ${ }^{12}$ The complexity of general movements increases and their number decreases, particularly during the last 10 weeks of pregnancy, as a result of maturation processes in the brainstem. Sleepwakefulness patterns become distinguishable in EEG at 30 weeks, as a result of the pontine maturation. The 
Table 1: Chronology of the prenatal neuromotor and neurosensory development (adapted from 2).

\begin{tabular}{|c|c|}
\hline Development of the fetal nervous system & Fetal motility \\
\hline \multicolumn{2}{|c|}{ Early first trimester } \\
\hline $\begin{array}{l}\text { Spinal cord-earliest sinapses: } 6-7 \text { weeks } \\
\text { Brainstem: } 7 \text { weeks }\end{array}$ & $\begin{array}{l}\text { Vermicular movements: 7- 7.5-slow flexion/extension of } \\
\text { fetal trunk }\end{array}$ \\
\hline Basic structures of the diencephalon and & First motor reflexes: 7.5 weeks \\
\hline cerebral hemispheres: End of the 8th week & General movements (head, trunk and limb movements): 8-9 weeks \\
\hline \multicolumn{2}{|c|}{ Late first trimester } \\
\hline Maturation of brainstem structures, primarily of the medulla & Isolated limb movements: 9 weeks \\
\hline oblongata: VIII-XII cranial nerves & Breathing-like movements: 10 weeks \\
\hline Pons: V-VIII cranial nerves & Head flexion and rotation: 10 weeks \\
\hline Midbrain: Maturation delayed & Facial movements-jaw opening, yawning: 10-11 weeks \\
\hline \multirow[t]{2}{*}{ Synapses in the cerebral cortex: End of the 10th week } & Handedness: 10 weeks \\
\hline & Goal orientation: 13 weeks \\
\hline
\end{tabular}

\section{Second trimester}

Maturation of the brainstem continues

Medulla oblongata-almost completely mature by the

end of this period

Formation of the subplate zone: 15-17 weeks of gestation

Synaptogenesis—most intensively: $15-20$ weeks

First electrocortical activity: 19 weeks

Spinothalamic tract: 20 weeks

Thalamocortical connections: $24-26$ weeks
High fetal activity: 14-19 weeks; quiescence periods only 5-6 minutes Eye movements: $16-18$ weeks

Organization of fetal motor patterns_-rest-activity cycles: 20 weeks

Facial movement patterns (except eye blinking)—a peak

frequency: End of the 2nd trimester

\begin{tabular}{|c|c|}
\hline \multicolumn{2}{|c|}{ Third trimester } \\
\hline Maturation of the midbrain and pons, continues & Eye blinking pattern—a peak frequency: 28 weeks \\
\hline Myelinization of the spinothalamic tract: 29 weeks & Facial expression patterns-decreasing or stagnant incidence \\
\hline Evoked potentials from the cerebral cortex: $26-28$ weeks & General movements-decrease in number, increase in complexity \\
\hline Beginning of the cortical areal differentiation: $24-34$ weeks & Eye movements-increase in complexity: $33-38$ weeks \\
\hline Lamination of the neocortex: 32 weeks onward & Establishment of the behavioral states: $36-38$ weeks \\
\hline Development of the nervous system & Fetal reaction \\
\hline \multicolumn{2}{|c|}{ First trimester } \\
\hline $\begin{array}{l}\text { Tactile sensation (the touch and pain) emerging first: } 7 \text { weeks } \\
\text { Development of nociceptors: From } 7 \text { weeks }\end{array}$ & $\begin{array}{l}\text { Perioral region, hands, lower limbs become touch sensitive: } \\
7.5,10.5 \text { and } 14 \text { weeks of gestation } \\
\text { Motor reflexes as first fetal response to painful stimuli: } 7.5 \text { weeks }\end{array}$ \\
\hline \multicolumn{2}{|l|}{ Development of taste buds: From 7 weeks } \\
\hline \multicolumn{2}{|c|}{ Second trimester } \\
\hline $\begin{array}{l}\text { Secretion of neuropeptide Y (NPY) and leptin: } 16-18 \text { weeks } \\
\text { Nociceptors present all over the body: } 20 \text { weeks } \\
\text { Thalamocortical pathways: Around the } 23 \text { rd week }\end{array}$ & $\begin{array}{l}\text { Possible regulation of appetite and ingestive behavior } \\
\text { Alterations in cerebra blood flow in response to painful } \\
\text { stimuli: } 16-18 \text { weeks } \\
\text { Elevation of cortisol and beta-endorphin levels in response to } \\
\text { painful stimuli: } 23 \text { weeks }\end{array}$ \\
\hline
\end{tabular}

Visual connections between retina, lateral geniculate

nucleus and visual cortex: Midgestation

Synaptogenesis in the primary visual cortex: From 24 weeks

Cochlear function: 22-25 weeks

\begin{tabular}{ll}
\hline & Third trimester \\
\hline $\begin{array}{l}\text { Somatosensory evoked potentials (pain processing } \\
\text { in the somatosensory cortex): } 29 \text { weeks }\end{array}$ & $\begin{array}{l}\text { Sense of pain: After } 26 \text { weeks } \\
\text { Response to pain as changes in facial activity, shifts in infant } \\
\text { sleep/wake state, physiological changes of heart rate and } \\
\text { blood oxygen saturation: After } 28 \text { weeks }\end{array}$ \\
\hline
\end{tabular}

Surface-positive evoked potentials in the visual and auditory cortex: From 36-40 weeks

Pons maturation
Tonotopic organization of the cochlear nuclei, maturation
of the brain stem: Last weeks of pregnancy
Fetal reactions to very loud sounds: From 26 weeks

Fetal response to external noise, discrimination between different sounds, selective preference for mother's voice: From 36 weeks 
complexity of eye movements increases as a result of the midbrain maturation. These movements become integrated with other parameters of fetal activity, such as heart rate and fetal movements, into organized behavioral states between 36 and 38 weeks of gestation. ${ }^{2,31,32}$

Contrary to the declining trend of head movement and hand movement patterns from the beginning of the second trimester to the end of the third trimester, our longitudinal analysis revealed that various types of facial movement patterns, for instance, mouthing, yawning, swallowing, grimacing displayed a peak frequency at the end of 2nd trimester (Table 1). During the 3rd trimester, decreasing or stagnant incidence of these motor patterns has been noted. ${ }^{18}$ This developmental trend provides yet another example of the maturation of the medulla oblongata, pons and midbrain, or possibly even the establishment of control of more cranial structures. The facts that even in the embryonic period same inductive forces that cause the growth and reshaping of the neural tube influence the development of facial structures, and that many genetic disorders affecting the CNS are also characterized by dysmorphology and dysfunction of facial structures, highlight the significance of structural and functional evaluation of the fetal face. ${ }^{13,33}$

The diverse repertoire of fetal movements raises the question of their function and significance for normal fetal development. It has been shown that fetal motor activity is fundamental for the development of most parts of the nervous system and the muscles. ${ }^{2}$

Our studies have also demonstrated that there were no movements observed in fetal life that were not present in neonatal life. Furthermore, prenatal-neonatal continuity exists even in subtle, fine movements, such as facial mimics. $^{34,35}$

\section{Development of Specialized Movement Patterns}

Specialized movement patterns, crucial for the survival of newborns, such as swallowing and respiratory movements, also develop and mature during gestation. Furthermore, these movements play an important role during intrauterine life. $^{2}$

Fetal breathing-like movements become visible at 10 weeks of gestation (Table 1). These brainstem reflexes occur more frequently as the medulla oblongata matures. ${ }^{12}$ Moreover, changes in the frequency and complexity of breathing-like patterns are consequences of the maturation of the fetal lungs as well as the respiratory and sleep centers in the CNS. During 38 and 39 weeks of gestation, the frequency of movements decreases to 41 respirations per minute and the movements become as regular as in the postnatal period. ${ }^{36}$ Recent data have indicated the role of fetal breathing-like movements in lung organogenesis. ${ }^{37}$
They are important for the normal lung development as well as the development of respiratory muscles, widening of the alveolar spaces, and maintenance of lung liquid volume. ${ }^{2}$

Fetal swallowing activity was observed as early as 11 weeks of gestation, ${ }^{38}$ with daily swallowing rates near term of 500 to $1000 \mathrm{ml} .{ }^{39}$ Fetal swallowing and ingestive behavior contribute significantly to the regulation of the amniotic fluid volume and the development and maturation of the fetal gastrointestinal tract. They also contribute to the fetal somatic growth. ${ }^{2}$

\section{External Factors and Fetal Movements}

It is important to recognize that both, the mother and the fetus, actively participate in the maintenance of the physiological intrauterine environment and in the fetal development. Unfortunately, the fetus is not entirely protected from harmful influence of the external factors. The fine interaction between external influences and endogenous fetal activity is revealed in the fact that fetal behavior may be influenced by a number of external factors. Cigarette smoking or injection of corticosteroids for fetal lung maturation have been shown to decrease the number of spontaneous fetal movements. ${ }^{40}$ Furthermore, fetal activity is increased in mothers suffering emotional stress. ${ }^{41}$ It has been known that qualitative alterations of spontaneous general movements can be observed in preterm and term newborns with cerebral impairment. ${ }^{42}$ Their movements seem to lose the characteristic fluency and complexity, and become cramped and unsynchronized. Similar qualitative alterations in fetal general movements have been observed in several conditions, including maternal diabetes mellitus, fetal anencephaly and intrauterine growth restriction (IUGR) ${ }^{42}$ It is interesting that preterm birth accelerates the maturation of kidney function, gastrointestinal function, and lung function but does not accelerate the development of all brain functions and may delay some of the early brain processes. ${ }^{43}$ Preterm birth delays the myelinization of the central nerve pathways. The cause of this delay is not known. Infants in the neonatal intensive care unit (NICU) are exposed to many stimuli, which would not occur in utero. For example, the fetus in utero is protected from exposure to high-pitched sound by the absorption of the sound in the tissues and fluid around the fetus, as opposed to the preterm infant who is exposed to frequent, high-pitched sound in the NICU. ${ }^{43}$

\section{FETAL SENSORY DEVELOPMENT}

\section{Development of Touch}

Normal intrauterine milieu provides an optimal, stimulating and interactive environment necessary for fetal development. 
Tactile sensations, such as touch and pain, are among the first to be developed during intrauterine life $^{2}$ (Table 1 ). Twin pregnancies allow observation of the first reactions to touch in utero. Perioral region, hands, lower limbs become touch sensitive at 7.5, 10.5 and 14 weeks of gestation respectively ${ }^{2}$ (Table 1). The evoked movements in early pregnancy can be explained only as the motor reflexes, driven by the spinal cord and its afferent-efferent circuits. First motor reflexes, head tilting after perioral touch, appear at the 7.5th gestational week. Between 10.5 and 14 weeks of gestation hands and lower limbs begin to participate in reflex movements. ${ }^{44}$ By 14 weeks of gestation most of the body, excluding the back and top of the head, is responsive to touch. ${ }^{43}$ The fetus's arms will make contact with its face from about 13 weeks of gestation, providing a source of stimulation. Further, if the fetus's lips or cheeks are touched at 8 to 9 weeks, it responds by moving its head away from the touch. However, later in pregnancy this response changes, and during the second trimester the fetus now moves toward the touch. ${ }^{43}$

Thalamocortical pathways, important for the perception of sensory impulses, reach the somatosensory cortex around the 23rd week (Table 1). These events are followed by the areal differentiation of the primary somatosensory cortex, as well as other primary cortical areas, between the 24th and 34th weeks. ${ }^{20,21}$ Maturation of the primary somatosensory cortex continues in the postnatal period. ${ }^{2}$

\section{Development of Pain}

The concept that the fetus is a patient in its own right and an enhanced understanding of fetal neurophysiology have led to increased interest in the subject of fetal pain. ${ }^{44,45}$ However, the question of fetal pain is not simple. Namely, any approach to this issue must account for pain as a neural process and as sensation as well as for the fetal perceptibility of noxiousness and the proximate and more durable effects of pain. It is also important to keep in mind impact of pain on the subsequent development and the activity of the CNS, and on potential life-long cognitive, emotional, behavioral, and other effects of fetal pain. ${ }^{45}$

The first nociceptors appear at 7 weeks of gestation, and by the 20th week these are present all over the body (Table 1). ${ }^{2}$ Sensing pain requires a develop neural pain system and, after 26 weeks, the fetus has the necessary connections to sense pain. Somatosensory evoked potentials (SEPs) can be registered from the cortex at 29 weeks, indicating that a functionally meaningful pathway from the periphery to the cerebral cortex starts to operate from that time onward ${ }^{7}$ (Table 1). Furthermore, SEPs may provide evidence of pain processing in the somatosensory cortex. ${ }^{46}$ The earliest reactions to painful stimuli, motor reflexes, can be detected at 7.5 weeks of gestation (Table 1 ). As early as 16 to 18 weeks, fetal cerebral blood flow increases during invasive procedures. ${ }^{47,48}$ An elevation of noradrenaline, cortisol and beta-endorphin plasma levels in response to needle pricking of the innervated hepatic vein for intrauterine transfusion, was registered in a 23-week-old fetus (Table 1). Pricking of the noninnervated placental cord insertion for the same purpose had no effect. ${ }^{49,50}$ Obviously, painful stimuli trigger a wide spectrum of reactions, such as activation of the hypothalamo-hypophysial axis or autonomic nervous system, without reaching the cortex. Hormonal, autonomic, and metabolic response to painful stimuli can be suppressed by analgesics. In premature neonates born after the 28th gestational week, the most promising pain indicators are changes in facial activity, shifts in infant sleep/wake state, and physiological changes of heart rate and blood oxygen saturation. ${ }^{51,52}$ One of the most important effects of a painful experience is the prolonged stress response. ${ }^{53}$ This includes marked fluctuations in blood pressure, cerebral blood flow and hypoxemia, which may predispose to intracranial hemorrhage. ${ }^{48}$ Moreover, prenatal and/or neonatal exposure to pain can lead to altered pain thresholds as well as abnormal pain-related behavior later in life. ${ }^{53}$

\section{Development of Vision}

The development of the vision, same like the other senses, is sensitive to environmental stimulation during prenatal and postnatal life. Vision is the sense least likely to be stimulated during the pregnancy. However, the intrauterine environment is not completely deprived of light. And the fetus may experience some general change in illumination. When tested under experimental conditions the fetus exhibits a change in the heart rate or movement when a bright light is flashed on the mother's abdomen from around 26 weeks of gestation, demonstrating that the visual system is operating to a certain extent. ${ }^{43}$ Also, according to some investigational results, the development of visual and auditory organs could not be possible without any light or auditory stimulation. ${ }^{54}$ Human visual connections between retina, lateral geniculate nucleus, and visual cortex are partially established by midgestation and undergo further development during and after this period. ${ }^{55}$ In the primary visual cortex, synaptogenesis persists between 24 weeks of gestation and 8 months after delivery (Table 1). Maturation of the visual cortex is characterized by the appearance of surface-positive evoked potentials, which occurs between the 36th and 40th week and continues after birth ${ }^{2}$ (Table 1 ). A flash stimulus over the maternal abdomen can cause the visual evoked brain activity in the human fetus, recorded by magnetoencephalography. Further, the fetal eye motility 
plays a role in retinal (neuronal) cell differentiation as well as eye functional maturation. ${ }^{2}$

As already mentioned, the development of the visual system is sensitive to environmental stimulation during prenatal and postnatal life. Animal study has demonstrated that maternal environmental enrichment (e.g. larger cage with extra-objects) stimulates the fetal structural maturation of the retina. ${ }^{56}$ Postnatal environmental enrichment, such as social interactions and sensory stimulation, results in a significant acceleration of visual system development, at behavioral, electrophysiological and molecular level. ${ }^{57-59}$

\section{Development of Hearing}

The fetus lives, not only in a stimulating matrix of motion, but also of sound and vibration. Although pregnant women have always noticed that their fetuses respond with body movements to loud external sounds, the questions of what stimuli are able to produce such an effect or how exactly the fetus responds to sounds did not intrigue many scientists prior to the 1980s. Just to the opposite, the opinion that fetal environment is isolated from the noise of the outer world was predominant at the time. ${ }^{60}$ The advent of the real-time sonography radically changed that opinion by permitting noninvasive visualization of fetal intrauterine activities. Studies have confirmed that the fetus can register and react to exogenous acoustic stimulation and that the character of fetal reactions changes as the pregnancy progresses. ${ }^{61}$

Cochlear function develops between 22 and 25 weeks of gestation, and its maturation continues during the first 6 months after delivery (Table 1 ). Fetal reactions to very loud sounds have been detected from 26 weeks onward. Delayed selective response to sounds can be explained by the prolonged pontine maturation. During the last weeks of pregnancy (from the 36th week onward), the fetus responds to external noise, even to the sound of mother's voice, with reflexive body movements, head-turning and heart-rate acceleration. But even more astonishing finding is that the fetus at this age is able not only to perceive the sounds, but also to discriminate between different sounds (Table 1). Furthermore, the fetus displays the selective preference for mother's voice or other familiar voices. These findings are explained by the tonotopic organization of the cochlear nuclei and by the maturation of the brainstem during the last weeks of pregnancy ${ }^{12}$ (Table 1). These findings also indicate that the brainstem displays learning-related activity. Fetuses less than 37 weeks of gestation of mothers, who smoke throughout pregnancy, have a delayed onset of response to the maternal voice. ${ }^{62}$ It is interesting that if the mother does not speak, a newborn may be 2 months delayed in development of the tonotopic column and less able to discern intensity, rhythm, and shape of each sound. ${ }^{36}$ Growth restriction could also affect the development of auditory perception in human fetuses. ${ }^{63}$

\section{Development of Taste, Thirst, Satiety and Appetite Mechanisms}

The chemical senses, such as the sense of taste, also develop during intrauterine life. Human embryos demonstrate taste buds by the 7 th week of gestation ${ }^{64}$ (Table 1). It has been shown that sweet taste stimulates swallowing in the human fetus, whereas bitter and sour tastes decrease fetal swallowing. Flavors from the mother's diet during pregnancy are transmitted to amniotic fluid and swallowed by the fetus. Consequently, the type of food eaten by the mother during pregnancy is experienced by the infants before their first exposure to solid food. ${ }^{65}$ It has also indicated that tendency to certain food acquires during intrauterine development. ${ }^{66}$

It is generally believed that thirst, satiety and appetite mechanisms develop prenatally in all precocious species. Experiments in fetal lambs have indicated that dipsogenic mechanisms begin to regulate swallowing during intrauterine life. Swallowing and arginine-vasopressin (AVP) secretion increase following the central administration of hypertonic saline solution and angiotensin II. According to some studies, an altered intrauterine osmotic environment may modulate not only fetal swallowing activity, but also the development of adult sensitivities for thirst, AVP secretion and AVP responsiveness. ${ }^{39,67,68}$ Mothers, consuming excessive amounts of salt and water during pregnancy increase salt preference in adult offspring which may lead to hypertension. ${ }^{69}$

The main feeding regulatory factors, neuropeptide $\mathrm{Y}$ (NPY) and leptin, are secreted in the human fetuses as early as 16 and 18 weeks respectively ${ }^{70-72}$ (Table 1). NPY is the most powerful known inducer of food intake and a leptin is a main satiety factor. Contrary to its function in adults, leptin does not suppress fetal ingestive behavior. ${ }^{67}$ Fetal swallowing was significantly increased following the injection of leptin. ${ }^{73}$ Therefore, some investigators have postulated that the lack of leptin-inhibitory responses might potentiate feeding and facilitate weight gain in newborns, despite high body fat levels. ${ }^{74}$

Further, it has been discussed that the mechanisms by which environmental factors modulate the physiologic systems that control body weight may have their roots before birth. ${ }^{75}$ An adverse intrauterine environment, with altered 
fetal orexic factors, could change the normal set-points of appetitive behavior and potentially lead to programming of childhood or/and adulthood hyperphagia and obesity. Further, prenatal exposure to over or undernutrition, rapid growth in early infancy, an early adiposity rebound in childhood, and early pubertal development have all been implicated in the development of obesity. ${ }^{76}$

\section{FETAL STRESS}

A large number of environmental factors can trigger the fetal stress response. For instance, maternal undernutrition or placental insufficiency can alter the intrauterine environment, causing fetal stress. ${ }^{77}$ Painful stimuli also lead to the fetal stress response. ${ }^{53}$ Even severe maternal emotional stress or stressful life events, according to some investigations, may influence the fetal environment. ${ }^{78-80}$

The primary role of stress is the protection of organism, but fetal exposure to stress may affect neurodevelopment, as well as the development of other organ systems, and have life-long consequences. Many adaptive changes induced by fetal stress increase the chance of fetal survival by creating a short-term protection. However, these changes can leave profound alterations in the structure and functions of the organism. ${ }^{77}$ It is a known fact that fetal cardiovascular adaptation to hypoxia is manifested by the redistribution of blood flow primarily toward the fetal brain. However, our investigations have shown that severe brain damage can develop despite the fetal blood flow redistribution and increased brain perfusion, even earlier than it was previously thought. $^{81}$

The neuroendocrine stress axis includes the production of the corticotropin releasing hormone ( $\mathrm{CRH})$, adrenocorticotropic hormone (ACTH) and cortisol. Fetal CRH has been shown to influence the timing of birth. These findings have pointed to an active role of the fetus in the initiation of parturition. ${ }^{82}$ Furthermore, ACTH impairs motor coordination and muscle tonicity, reduces attention span and increases irritability. ${ }^{77}$ Recently, epidemiological and experimental investigations have showed that chronic exposure to high levels of cortisol during intrauterine life, occurring either as a result of its exogenous application or the maternal stress, has a very adverse effect in the long run. ${ }^{83-87}$ Unfortunately, it has been established that cortisol, which accelerates lung maturation and enables survival of premature infants, may have a negative influence on growth of the lungs, development of the secondary alveolar septa, and even on the growth of the whole organism. ${ }^{83}$ Accelerated maturation of the brain is associated with the structural as well as behavioral changes. Stress induces structural changes of the hippocampus ${ }^{84-87}$ that are associated with memory impairment and learning disabilities. Behavioral changes associated with accelerated maturation of the brain include hyperalertness and impaired fetal responsiveness to novel stimuli. ${ }^{88}$ Retrospective studies on children whose mothers experienced severe psychological stress or adverse life events during their pregnancy have suggested long-term neurodevelopment effects on the infant. ${ }^{89-92}$ Such children exhibited symptoms of attention deficit hyperactivity disorder, sleep disorders, unsociable and inconsiderate behavior as well as psychiatric disorders, including schizophrenic episodes, depressive and neurotic symptoms, drug abuse and anxiety. ${ }^{93}$ Increased maternal stress during pregnancy seems to influence infant temperament and cognitive functions. ${ }^{94,95}$ Moreover, stressful maternal life events measured during the first part of pregnancy negatively affected the child's attention/ concentration index measured at the age of six. ${ }^{96}$ Fortunately, recent evidence have shown that increased maternal care and environmental enrichment can compensate for prenatal stress-induced effects. ${ }^{97-99}$ We can conclude that some of the most common neurologic dysfunctions can have their origins in prenatal life.

\section{CONCLUSION}

So far, studies carried out by 4D ultrasound have shown that fetal motoric parameters and fetal behavior are valuable indicators of the functional and structural brain development. Furthermore, it has been shown that the fetus needs stimulating matrix of movements, sounds, vibrations and other stimuli for normal neurodevelopment and development of other organs and organ systems. Neurophysiology also teaches us that the fetus needs stressfree environment for the normal development of brain and other organs, as well as for normal somatic growth.

\section{REFERENCES}

1. Nijhuis JG. Fetal behavior. Neurobiol Aging 2003;24,41-46.

2. Salihagic Kadic A, Predojevic M, Kurjak A. Advances in fetal neurophysology. In: Pooh RK, Kurjak A (Ed). Fetal neurology. New Delhi: Jaypee Brothers Medical Publishers 2009;161-221.

3. Andonotopo W, Stanojevic M, Kurjak A, Azumendi G, Carrera JM. Assessment of fetal behavior and general movements by four-dimensional sonography. Ultrasound Rev Obstet Gynecol 2004;4:103-14.

4. Okado N, Kakimi S, Kojima T. Synaptogenesis in the cervical cord of the human embryo: Sequence of synapse formation in a spinal reflex pathway. J Comp Neurol 1979;184:491-518.

5. Okado N. Onset of synapse formation in the human spinal cord. J Comp Neurol 1981;201:211-19.

6. de Vries JIP, Visser GHA, Prechtl HFR. The emergence of fetal behavior I. Qualitative aspects. Early Human Dev 1982;7: 301-22. 
7. Stafstrom CE, Johnston D, Wehner JM, Sheppard JR. Spontaneous neural activity in fetal brain reaggregate culture. Neuroscience 1980;1681-89.

8. Streit J. Regular oscillations of synaptic activity in spinal networks in vitro. J Neurophysiol 1993;70:871-78.

9. Kostovic I, Judas M. Transient patterns of cortical lamination during prenatal life: Do they have implications for treatment? Neurosci Biobehav Rev 2007;31(8):1157-68.

10. Voigt T, Opitz T, de Lima AD. Synchronous oscillatory activity in immature cortical network is driven by GABAergic preplate neurons. J Neurosci 2001;21(22):8895-905.

11. Albrieux M, Platel JC, Dupuis A, et al. Early expression of sodium channel transcripts and sodium current by cajal-retzius cells in the preplate of the embryonic mouse neocortex. J Neurosci 2004;24(7):1719-25.

12. Joseph R. Fetal brain and cognitive development. Dev Rev 1999;20:81-98.

13. Pomeroy SL, Volpe JJ. Development of the nervous system. In: Polin RA, Fox WW (Eds): Fetal and neonatal physiology. Phyladelphia-London-Toronto-Montreal-Sydney-Tokyo: WB Saunders Copmany 1992;1491-509.

14. McCartney G, Hepper P. Development of lateralized behavior in the human fetus from 12 to 27 weeks' gestation. Dev Med Child Neurol 1999;41(2):83-86.

15. Hepper PG, McCartney GR, Shannon EA. Lateralised behavior in first trimester human foetuses. Neuropsychologia 1998;36(6):531-34.

16. Kurjak A, Azumendi G, Vecek N, et al. Fetal hand movements and facial expression in normal pregnancy studied by fourdimensional sonography. J Perinat Med 2003;31:496-508.

17. Pooh RK, Ogura T. Normal and abnormal fetal hand positioning and movement in early pregnancy detected by three- and fourdimensional ultrasound. Ultrasound Rev Obstet Gynecol 2004;4:46-51.

18. Kurjak A, Andonotopo W, Hafner T, et al. Normal standards for fetal neurobehavioral developments-longitudinal quantification by four-dimensional sonography. J Perinat Med 2006;34:56-65.

19. Andonotopo W, Medic M, Salihagic-Kadic A, et al. The assessment of fetal behavior in early pregnancy: Comparison between 2D and 4D sonographic scanning. J Perinat Med 2005;33(5):406-14.

20. Kostovic I, Rakic P. Developmental history of the transient subplate zone in the visual and somatosensory cortex of the macaque monkey and human brain. J Comp Neurol 1990;274:441-70.

21. Kostovic I, Judas M, Petanjek Z, Simic G. Ontogenesis of goaldirected behavior: Anatomo-functional considerations. Int J Psychophysiol 1995;19(2):85-102.

22. de Vries JIP, Visser GHA, Mulder EJH, Prechtl HFR. Diurnal and other variations in fetal movement and heart rate patterns at 20-22 weeks. Early Hum Dev 1987;15(6):333-48.

23. Seron-Ferre M, Ducsay CA, Valenzuela GJ. Circadian rhythms during pregnancy. Endocr Rev 1993;14(5):594-609.

24. Visser GHA, Laurini RN, Vries JIP, et al. Abnormal motor behaviour in anencephalic fetuses. Early Human Dev 1985;12:173-83.

25. Visser GHA, Prechtl HFR. Perinatal neurological development. Proceedings of the Third International Conference on Fetal and Neonatal Physiological Measurements III. 1989:335-46.
26. Kostovic I, Rakic P. Development of prestriate visual projections in the monkey and human fetal cerebrum revealed by transient cholinesterase staining. J Neurosci 1984;4:25-42.

27. Kostovic I, Goldman-Rakic PS. Transient cholinesterase staining in the mediodorsal nucleus of the thalamus and its connections in the developing human and monkey brain. J Comp Neurol 1983;219:431-47.

28. Amiel-Tison C, Gosselin J. From neonatal to fetal neurology: Some clues for interpreting fetal findings. In: Pooh RK, Kurjak A (Eds). Fetal neurology. New Delhi: Jaypee Brothers Medical Publishers 2009.

29. Klimach VJ, Cooke RW. Maturation of the neonatal somatosensory evoked response in preterm infants. Dev Med Child Neurol 1988;30:208-14.

30. Kostovic I, Judas M, Rados M, Hrabac P. Laminar organization of the human fetal cerebrum revealed by histochemical markers and magnetic resonance imaging. Cereb Cortex 2002;12: 536-44.

31. Visser GHA, Mulder EJH, Prechtl HFR. Studies on developmental neurology in the human fetus. Dev Pharmacol Ther 1992;18:175-83.

32. Mulder EJH, Visser GHA, Bekedan DJ, Prechtl HFR. Emergence of behavioural states in fetuses of type-1 diabetic women. Early Huma Dev 1987;15:231-52.

33. Merz E, Weller C. 2D and 3D ultrasound in the evaluation of normal and abnormal fetal anatomy in the second and third trimesters in a level III center. Ultraschall in Med 2005;26: 9-16.

34. Kurjak A, Stanojevic M, Andonotopo W, et al. Behavioral pattern continuity from prenatal to postnatal life: A study by four-dimensional (4D) ultrasonography. J Perinat Med 2004; 32:346-53.

35. Stanojevic M, Kurjak A, Salihagic-Kadic A, Vasilj O, Miskovic B, Shaddad AN, et al. Neurobehavioral continuity from fetus to neonate. J Perinat Med 2011;39:171-77.

36. Patrick J, Campbell K, Carmichael L, et al. A definition of human fetal apnea and the distribution of fetal apneic intervals during the last 10 weeks of pregnancy. Am J Obstet Gynecol 1978;136:371-77.

37. Inanlou MR, Baguma-Nibasheka M, Kablar B. The role of fetal breathing-like movements in lung organogenesis. Histol Histopathol 2005;20:1261-66.

38. Diamant NE. Development of esophageal function. Am Rev Respir Dis 1985;131:S29-32.

39. Ross MG, Nijland JM. Development of ingestive behavior. Am J Physiol 1998;274:R879-93.

40. Graca LM, Cardoso CG, Clode N and Calhaz-Jorge C. Acute effects of maternal cigarette smoking on fetal heart rate and fetal movements felt the mother. J Perinat Med 1991;19: 385-90.

41. Katz M, Meizner I, Holcberg G, et al. Reduction of cessation of fetal movements after administration of steroids for enhancement of lung maturation. Isr J Med Science 1988;24:5-9.

42. Prechtl HFR and Einspieler C. Is neurological assessment of the fetus possible? Eur J Obstet Gynecol Reprod Biol 1997;75:81-84.

43. Hepper P. Prenatal development. In: Slater A, Lewis M (Eds). Introduction to infant development. New York: Oxford University Press 2007:39-101. 
44. Vanhatalo S, van Nieuvenhuizen O. Fetal pain. Brain Dev 2000;22(3):145-50.

45. Gupta A, Giordano J. On the nature, assessment, and treatment of fetal pain: Neurobiological bases, pragmatic issues, and ethical concerns. Pain Physician 2007;10(4):525-32.

46. Lee SJ, Ralston HJ, Drey EA, Partridge JC, Rosen MA. Fetal pain: A systematic multidisciplinary review of the evidence. JAMA 2005;294:947-54.

47. Teixeira JM, Glover V, Fisk NM. Acute cerebral redistribution in response to invasive procedures in the human fetus. Am J Obstet Gynecol 1999;181(4):1018-25.

48. Smith RP, Gitau R, Glover V, et al. Pain and stress in the human fetus. Eur J Obstet Gynecol Reprod Biol 2000;92:161-65.

49. Giannakoulopoulos X, Sepulveda W, Kourtis P, et al. Fetal plasma cortisol and beta endorphin response to intrauterine needling. Lancet 1994;344:77-81.

50. Giannakoulopolous X, Teixeira J, Fisk N, et al. Human fetal and maternal noradernaline responses to invasive procedures. Pediatr Res 1999;45:494-99.

51. Stevens BJ, Johnston CC, Grunau RVE. Issues of assessment of pain and discomfort in neonates. J Obstet Gynecol Neonatal Nurs 1995;24:849-55.

52. Stevens B, Johnston CC, Petryshen P, Taddio A. The premature infant pain profile. Clin J Pain 1996;12:13-22.

53. Anand KJS. Clinical importance of pain and stress in preterm neonates. Biol Neonate 1998;73:319-24.

54. Magoon EH, Robb RM. Development of myelin in human optic nerve tract. A light and electron microscopic study. Arch Ophtalmol 1981;99:655-59.

55. Hevner RF. Development of connections in the human visual system during fetal mid-gestation: A DiI-tracing study. J Neuropathol Exp Neurol 2000;59(5):385-92.

56. Sale A, Cenni MC, Ciucci F, et al. Maternal enrichment during pregnancy accelerates retinal development of the fetus. HPLoS ONE 2007;2(11):e1160.

57. Cancedda L, Putignano E, Sale A, et al. Acceleration of visual system development by environmental enrichment. J Neurosci 2004;24(20):4840-48.

58. Sale A, Putignano E, Cancedda L, et al. Enriched environment and acceleration of visual system development. Neuropharmacology 2004;47(5):649-60.

59. Landi S, Sale A, Berardi N, Viegi A, Maffei L, Cenni MC. Retinal functional development is sensitive to environmental enrichment: A role for BDNF. FASEB J 2007;21(1):130-39.

60. Lecanuet JP, Schaal B. Fetal sensory competencies. Eur J Obstet Gyonecol Reprod Biol 1996;68:1-23.

61. Hepper P, Shahidullah S. Development of fetal hearing. Arch Dis Child 1994;71:81-87.

62. Cowperthwaite B, Hains SM, Kisilevsky BS. Fetal behavior in smoking compared to non-smoking pregnant women. Infant Behav Dev 2007;30(3):422-30.

63. Marshall J. Infant neurosensory development: Considerations for infant child care. Early Childhood Education Journal 2011;39:1-7.

64. Bradley RM, Mistretta CM. The developing sense of taste. In: Denton, Coghlan JP. Olfaction and Taste VDA. New York: Academic 1975:91-98.

65. Mennella JA, Johnson A, Beauchamp GK. Garlic ingestion by pregnant women alters the odor of amniotic fluid. Chem Senses 1995;20(2):207-09.

66. Mennella JA, Jagnow CP, Beauchamp GK. Prenatal and postnatal flavor learning by human infants. Pediatrics 2001;107(6):E88.
67. El-Haddad MA, Desai M, Gayle D, Ross MG. In utero development of fetal thirst and appetite: Potential for programming. J Soc Gynecol Investig 2004;11(3):123-30.

68. Nicolaidis S, Galaverna O, Meltzer CH. Extracellular dehydration during pregnancy increases salt appetite of offspring. Am J Physiol (Regulatory Integrative Comp Physol) 1990;258:281-83.

69. Vijande M, Brime JI, López-Sela P, et al. Increased salt preference in adult offspring raised by mother rats consuming excessive amounts of salt and water. Regul Pept 1996;66 (1-2):105-08

70. Kawamura K, Takebayashi S. The development of noradrenaline-acetylcholinesterase-, neuropeptide $\mathrm{Y}$ - and vasoactive intestinal polypeptide-containing nerves in human cerebral arteries. Neurosci Lett 1994;175:1-4.

71. Cetin I, Morpurgo PS, Radaelli T, et al. Fetal plasma leptin concentrations: Relationship with different intrauterine growth patterns from 19 weeks to term. Pediatr Res 2000;48:646-51.

72. Jaquet D, Leger J, Levy-Marchal C, et al. Ontogeny of leptin in human fetuses and newborns: Effect of intrauterine growth retardation on serum leptin concentrations. J Clin Endocrinol Metab 1998;83:1243-46.

73. Roberts TJ, Nijland MJ, Caston-Balderrama A, et al. Central leptin stimulates ingestive behavior and urine flow in the near term ovine fetus. Horm Metab Res 2001;33:144-50.

74. Ross MG, El Haddad M, DeSai M. Unopposed orexic pathways in the developing fetus. Physiol Behav 2003;79(1):79-88.

75. Breier BH, Vickers MH, Ikenasio BA, et al. Fetal programming of appetite and obesity. Mol Cell Endocrinol 2001;185(1-2): 73-79.

76. Adair LS. Child and adolescent obesity: Epidemiology and developmental perspectives. Physiol Behav 2008;94:8-16.

77. Salihagic Kadic A, Medic M, Kurjak A. Recent advances in neurophysiology. In: Kurjak A, Azumendi G (Eds). The fetus in three dimensions. London:Informa Healtcare 2007:411-33.

78. Carmichael SL, Shaw GM, Yang W, Abrams B, Lammer EJ. Maternal stressful life events and risks of birth defects. Epidemiology 2007;18(3):356-61.

79. Monk C, Fifer WP, Myers MM, et al. Maternal stress responses and anxiety during pregnancy: Effects on fetal heart rate. Dev Psychobiol 2000;36(1):67-77.

80. DiPietro JA, Hilton SC, Hawkins M, et al. Maternal stress and affect influence fetal neurobehavioral development. Dev Psychol 2002;38(5):659-68.

81. Salihagic-Kadic A, Medic M, Jugovic D, Kos M, Latin V, Kusan Jukic M, Arbeille P. Fetal cerebrovascular response to chronic hypoxia-implications for the prevention of brain damage. J Matern Fetal Neonatal Med 2006;19(7):387-96.

82. Howe DC, Gertler A, Challis JR. The late gestation increase in circulating ACTH and cortisol in the fetal sheep is suppressed by intracerebroventricular infusion of recombinant ovine leptin. J Endocrinol 2002;174:259-66.

83. Hundertmark S, Ragosch V, Zimmermann B, et al. Effect of dexamethasone, triiodothyronine and dimethyl-isopropylthyronine on lung maturation of the fetal rat lung. J Perinat Med 1999;27(4):309-15.

84. Uno H, Lohmiller L, Thieme C, et al. Brain damage induced by prenatal exposure to dexamethasone in fetal rhesus macaques. I. Hippocampus. Brain Res Dev Brain Res 1990;53:157-67.

85. Barbazanges A, Piazza PV, Le Moal M, Maccari S. Maternal glucocorticoid secretion mediates long-term effects of prenatal stress. J Neurosci 1996;16:3943-49. 
86. Hayashi A, Nagaoka M, Yamada K, et al. Maternal stress induces synaptic loss and developmental disabilities of offspring. Int J Dev Neurosci 1998;16:209-16.

87. Rees S, Harding R. Brain development during fetal life: Influences of the intrauterine environment. Neursci Lett 2004;361:111-14.

88. Sandman CA, Wadhwa PD, Chicz-Demet A, et al. Maternal corticortropin-releasing hormone and habituation in human fetus. Dev Psychobiol 1999;34:163-73.

89. Glover V. Maternal stress or anxiety in pregnancy and emotional development of the child. Br J Psychiarey 1997;171:105-06.

90. Graham YP, Heim C, Goodman SH, et al. The effects of neonatal stress on brain development: Implications for psychopathology. Dev Psychopatol 1999;11:545-65.

91. Weinstock M. Does prenatal stress impair coping and regulation of hypothalamic-pituitary-adrenal axis. Neurosci Biobehav Rev 1997;21:1-10.

92. Weinstock M. Alterations induced by gestational stress in brain morphology and behaviour of the off-spring. Prog Neurobiol 2001;65:427-51.

93. Amiel-Tison C, Vabrol D, Denver R, et al. Fetal adaptation to stress Part II. Evolutionary aspects; stress induced hippocampal damage; long-term effects on behavior; consequences on adult health. Early Human Dev 2004;78:81-94.

94. Buitelaar JK, Huizink AC, Mulder EJ, de Medina PG, Visser GH. Prenatal stress and cognitive development and temperament in infants. Neurobiol Aging 2003;24(Suppl 1):S53-60.

95. Davis EP, Glynn LM, Schetter CD, Hobel C, Chicz-Demet A, Sandman CA. Prenatal exposure to maternal depression and cortisol influences infant temperament. J Am Acad Child Adolesc Psychiatry 2007;46(6):737-46.

96. Gutteling BM, de Weerth C, Zandbelt N, Mulder EJ, Visser GH, Buitelaar JK. Does maternal prenatal stress adversely affect the child's learning and memory at age six? J Abnorm Child Psychol 2006;34(6):789-98.

97. Cladji C, Dioro J, Meaney MJ. Variations in maternal care in infancy regulate the development of stress reactivity. Biol Psychiatry 2000;48:1164-74.

98. Francis DD, Diorio J, Plotsky PM, Meaney MJ. Environmental enrichment reverses the effects of maternal separation on stress reactivity. J Neurosci 2002;22:7840-43.

99. Yang J, Hou C, Ma N, et al. Enriched environment treatment restores impaired hippocampal synaptic plasticity and cognitive deficits induced by prenatal chronic stress. Neurobiol Learn Mem 2007;87(2):257-63.

\section{ABOUT THE AUTHORS}

\section{Aida Salihagić-Kadić}

Department of Physiology, Medical School, University of Zagreb Croatian Institute for Brain Research, Medical School, University of Zagreb, Zagreb, Croatia

\section{Maja Predojevic (Corresponding Author)}

Department of Obstetrics and Gynecology, University Hospital 'Sveti Duh', Medical School, University of Zagreb, Sveti Duh 64, 10000 Zagreb, Croatia, e-mail: predojevic.maja@gmail.com 